\title{
APLIKASI INFORMASI CUACA EKSTRIM DAN GEMPA BUMI
}

\author{
Fakultas Teknologi Informasi \\ Universitas Islam KalimantanMuhammad Arsyad Al Banjari Banjarmasin \\ Yusri Ikhwani \\ yusri.ikhwani@gmail.com
}

\begin{abstract}
ABSTRAK
Badan Meteorologi, Klimatologi dan Geofisika (BMKG) adalah Lembaga Pemerintah Non Departemen sesuai dengan Undang-undang Republik Indonesia Nomor 31 Tahun 2009 tentang Meteorologi, Klimatologi dan Geofisika.

Kondisi alam dan geografis Negara Kesatuan Republik Indonesia yang merupakan negara kepulauan terletak pada pertemuan empat lempeng tektonik yaitu lempeng Benua Asia, Benua Australia, lempeng Samudera Hindia dan Samudera Pasifik yang suatu saat terjadi interaksi yang berakibat terjadinya gempa dan juga merupakan negara yang memiliki begitu banyak gunung berapi aktif.

Wilayah Negara Kesatuan Republik Indonesia terletak di daerah iklim tropis dengan dua musim yaitu panas dan hujan dengan ciri-ciri adanya perubahan cuaca, suhu dan arah angin yang cukup ekstrim sehingga sering terjadi banjir dan tanah longsor.

Di era digital suatu informasi sangat bermanfaat bagi masyarakat, dimana informasi penting harus cepat tersebar ke masyarakat yang berasal dari suatu lembaga resmi agar informasi yang didapat oleh masyarakat bukan suatu informasi yang menyesatkan atau hoax. Adapuntujuan yang akan Dicapai dalam penelitian ini menganalisa, merancang dan mengimplemetasikan suatu sistem yang dapat memberikan informasi valid ke masyarakat secara cepat dan akurat sesuai dengan motto dari BMKG yaitu cepat, tepat, akurat, luas dan mudah difahami. Hasil dalam penelitian ini adalah dapat diterapkannya aplikasi informasi peringatan dini cuaca yang ekstrim dam gempa bumi serta informasi yang diberikan ke masyarakat berupa pesan pendek SMS secara cepat, tepat, akurat, dan mudah difahami oleh masyarakat.
\end{abstract}

Kata Kunci : BMKG, Cuaca, Gempa, SMS Gateway

\section{PENDAHULUAN}

Perkembangan teknologi informasi dan komunikasi di Negara Kesatuan Republik Indonesia sudah sangat berkembang luar biasa pesat, perkembangan tersebut bisa dimanfaatkan sebaik mungkin dan pekerjaan-pekerjaan di dalam suatu organisasi dapat diselesaikan secara cepat, akurat dan efisien. Salah satu bidang teknologi yang berkembang sangat cepat adalah teknologi komunikasi yang meliputi hardware dan software, hardware yang terdiri dari alat-alat elektronik semakin banyak ditemukan oleh pengguna, dikarenakan dapat memenuhi kebutuhan akan sesuatu yang efektif dan efisien, salah satunya telepon seluler (ponsel) yang mempunyai kelebihan bisa dibawa kemana-mana baik di kantor, di rumah, di kampus, di jalan atau di tempat lainnya, sehingga seseorang dapat saling berkomunikasi dengan 
cepat tanpa dibatasi ruang atau posisi dimana seseorang itu berada.

Salah satu fitur yang ada pada telepon seluler adalah layanan seperti pesan data pendek atau Short Message Service (SMS) pada sistem GSM. Kita tidak pernah menyangka layanan SMS sedemikian sering digunakan orang. Kegemaran pengguna telepon seluler dalam ber-SMS dikarenakan lebih murah, praktis dan terdapat pada semua jenis serta tipe ponsel baik yang harga mahal atau pun dengan harga yang sangat terjangkau, membuat fitur yang satu ini tetap digemari dan bertahan hingga saat ini.

Badan Meteorologi, Klimatologi dan Geofisika (BMKG) merupakan sebuah instansi yang menangani tentang informasi data gempa, iklim, informasi cuaca, informasi suhu udara, kelembaban, lama penyinaran matahari, tekanan udara di seluruh wilayah Negara Kesatuan Republik Indonesia yang dilakukan pencatatan update perhari dan dalam kurun waktu tertentu seperti prakiraan cuaca esok hari, prakiraan cuaca seminggu kedepan, iklim dan lain-lain yang dapat digunakan untuk tujuan penelitian.

Berdasarkan perkembangan tersebut maka di analisa permasalahan dan membuat rancang sistem sampai dengan implementasi menjadi sebuah aplikasi yang memberikan informasi cepat kepada masyarakat tentang cuaca ekstrim ataupun gempa dan lain-lain dengan menggunakan aplikasi yang berbasis SMS gateway agar informasi yang disampaikan kepada masyarakat bisa cepat dan akurat kemudian menjangkau daerah-daerah terpencil yang terdampak.

\section{RUMUSAN MASALAH}

Berdasarkan latar belakang permasalahan diatas, dapat dibuat suatu rumusan masalah yaitu bagaimana menganalisa, merancang dan mengimplementasikan sistem yang dibuat menjadi aplikasi dapat berguna bagi masyarakat sehingga dapat mengetahui informasi valid dari pihak yang berwenang tentang peringatan sedini mungkin.

\section{TUJUAN PENELITIAN}

Tujuan penelitian yang ingin dicapai dalam penelitian ini adalah menganalisa, merancang dan mengimplemetasikan suatu sistem yang dapat memberikan informasi valid ke masyarakat secara cepat dan akurat sesuai dengan motto dari BMKG yaitu cepat, tepat, akurat, luas dan mudah difahami.

METODE PENELITIAN Tahap-tahap metode penelitian

yang dilakukan dengan tahapan penelitian seperti berikut:

\section{Analisa}

Tahapan ini dilakukan proses observasi lapangan dengan melakukan wawancara, pengumpulan data dan studi pustaka.

\section{Perancangan Sistem}

Tahapan ini dikerjakan apabila tahap analisa sudah dikerjakan dan rancangan sistem dibuat sesuai dengan kebutuhan-kebutuhan yang didapat ketika proses analisa lapangan dikerjakan.

\section{Implementasi}

Setelah tahapan rancangan sudah dikerjakan maka tahap selanjutnya adalah mengimplementasikan sistem sesuai dengan rancangan dibuat dengan menggunakan bahasa pemrograman Delphi dan database MySql.

\section{Pengujian}

Dari hasil implementasi perlu proses untuk pengujian sistem untuk mengetahui apakah ada kesalahan sistem dan pengujian juga sebagai bahan untuk evaluasi terhadap sistem yang dibuat. 


\section{PEMBAHASAN}

\section{Struktur SMS Gateway}

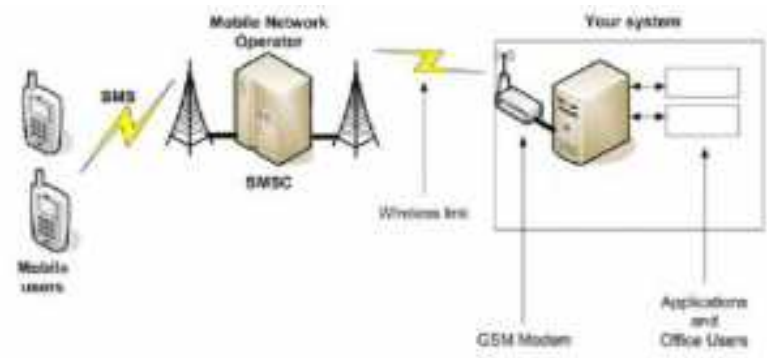

2. Implementasi Sistem

Hasil dari implementasi sistem sebagai berikut,

- Proses yang akan ditampilkan pada sistem ini adalah menu utama. Berikut gambar menu utama dari sistem yang dibuat:

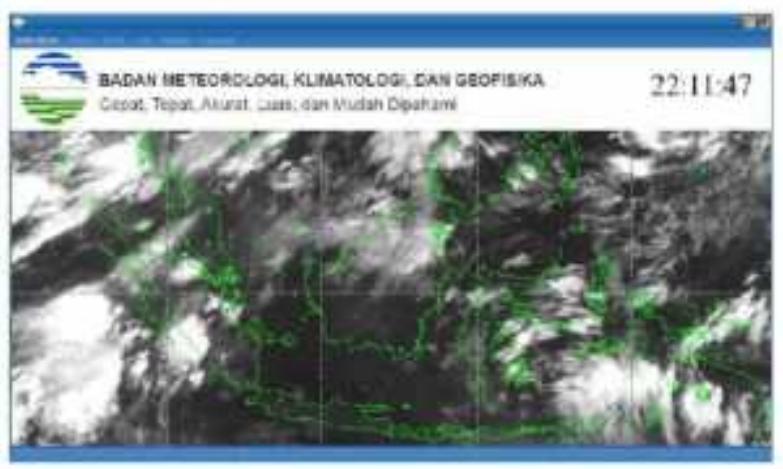

- Proses untuk melakukan pendataan nomor handphone dalam sistem ini adalah pada form inbox. Berikut gambar form inbox dari sistem yang dibuat:

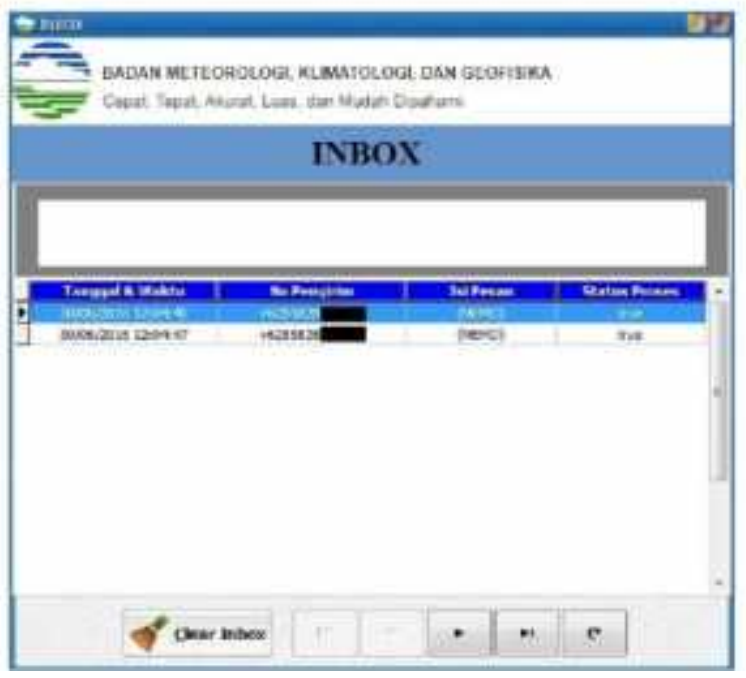

- Proses untuk melakukan pendataan penyebaran informasi ke nomor handphone yang sudah terdaftar. Berikut gambar form outbox dari sistem yang dibuat:

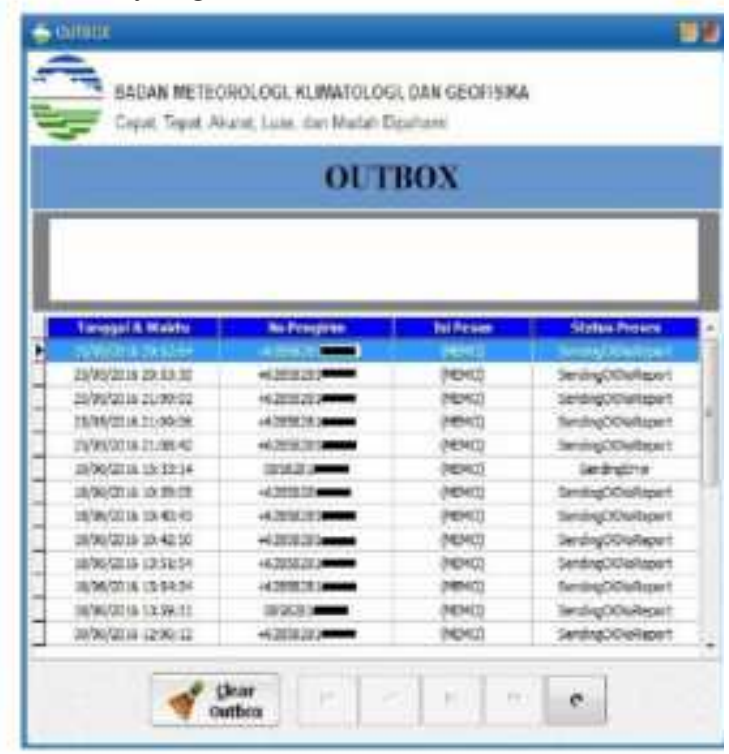

- Proses sistem melakukan penyebaran informasi/broadcast valid peringatan dini secara otomatis yang disebar sesuai dengan nomor handphone yang terdaftar kepada masyarakat luas sesuai area terdampak. Berikut gambar form broadcast message dari sistem yang dibuat:

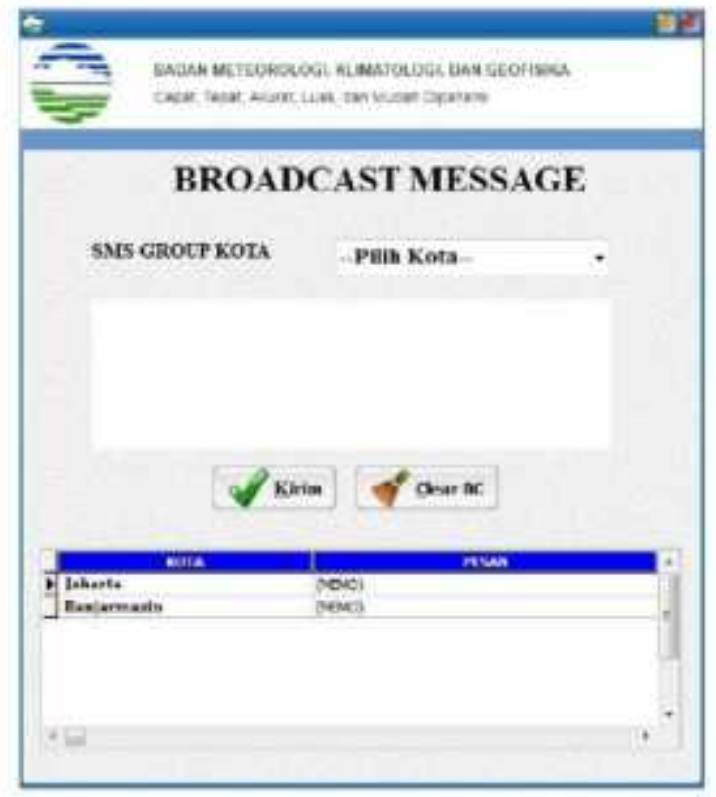


- Ada berbagai macam data yang selalu di update oleh BMKG, salah satu contoh adalah data curah hujan. Berikut gambar data curah hujan dari sistem yang dibuat:

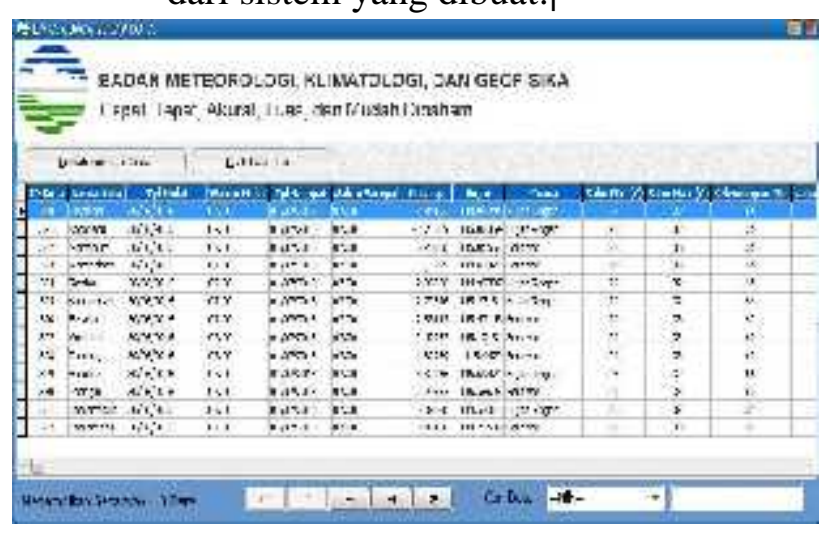

- Data Gempa Bumi yang terjadi dan sistem akan mengirim pesan pemberitahuan ke masyarakat sesuai dengan wilayah yang terkena dampak gempa. Berikut gambar data gempa di sistem:

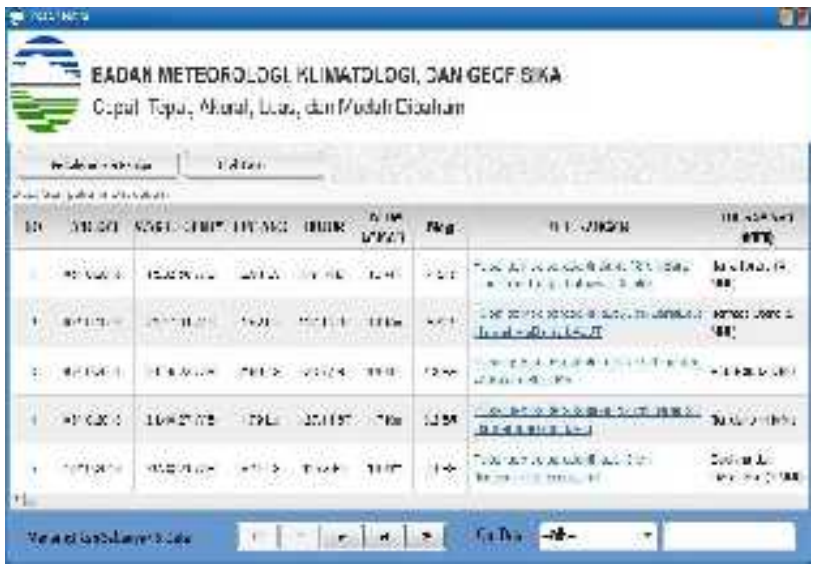

\section{Pengujian Sistem}

Pengujian pertama yang dilakukan adalah apakah informasi pesan untuk masyarakat terkirim, berikut laporan log outbox dimana pada laporan ini akan diketahui pesan terkirim kepada masyarakat.

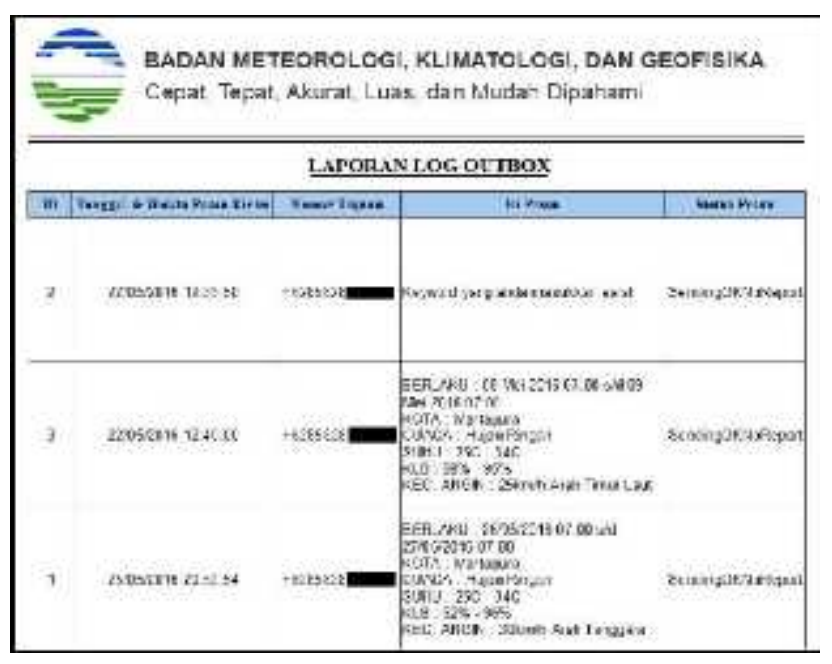

\section{PENUTUP}

\section{Kesimpulan}

Berdasarkan hasil penelitian yang telah dilakukan dimulai dari analisa, perancangan dan implementasi terhadap Aplikasi tentang informasi peringatan dini kondisi alam yang ekstrim dapat diterapkan dengan baik sehingga masyarakat akan mudah mengetahui informasi tentang peringatan dini yang sumber informasinya dari lembaga resmi dan terpercaya demi menghindari informasi hoax dan informasi yang di share melalui sms dapat terkirim pada daerah terdampak walaupun daerah terisolasi karena daya jangkau SMS masih terpenuhi.

\section{Saran}

Berdasarkan kesimpulan di atas, maka ada beberapa saran yang dapat disampaikan :

Saran-saran yang dikemukakan adalah dan sebagai bahan pertimbangan untuk pengembangan lebih lanjut terhadap sistem yang dibuat adalah sebagai berikut.

- Fitur aplikasi dapat dikembangkan, seperti informasi atau data tsunami dengan memanfaatkan alat pemancar yang dipasang dipesisir pantai. 


\section{DAFTAR PUSTAKA}

[1] Al-Bahra bin Ladjamudin.2005. Analisis dan Desain Sistem Informasi. Yogyakarta : Graha Ilmu.

[2] Andi. 2003. Pemrograman Borland Delphi 7.0, PT. Andi, Yogyakarta

[3] Arbie. (2004). Manajemen Database dengan MySql. Yogyakarta: Andi.

[4] BMKG.(2017). "Profil BMKG". 2017.http://www.bmkg.go.id/profil.

[5] BNPB.(2017)."Sejarah BNPB". 2017.https://bnpb.go.id//home/sejarah.

[6] Budi Warsito and Sri Sumiyati, Prediksi Curah Hujan Kota Semarang Dengan FeedForward NN Menggunakan Algoritma Quasi Newton BFGS dan Levenberg-Marquardt, 2005.

[7] Kadarsah and Ahmad Sasmita, "Standardisasi Metadata Klimatologi Dalam Penelitian Perubahan Iklim Di Indonesia," in Prosiding PPI Standardisasi 2010, Banjarmasin, 2010, pp. 1-18.

[8] Yusri Ikhwani, Mayang Sari, Wahyudi Fajar Persada. "Aplikasi Tarif Pelayanan Jasa Meteorologi Berbasis Client Server" Jurnal TECHNOLOGIA (2017):34-40

[9] Yusri Ikhwani. "Perbandingan Algoritma Levenberg Marquardt, Scale Conjugate Gradient Dan Gradient Descent With Adaptive Learning Rate Dalam Prediksi Rentet Waktu Curah Hujan" Jurnal TECHNOLOGIA(2015) 